\title{
Knee extensor torque of men with early degrees of osteoarthritis is associated with pain, stiffness and function
}

\author{
Homens com graus iniciais de osteoartrite apresentam correlação entre torque \\ extensor do joelho e dor, rigidez e função
}

Paula R. M. S. Serrão, Karina Gramani-Say, Giovanna C. Lessi, Stela M. Mattiello

\begin{abstract}
Background: Osteoarthritis $(\mathrm{OA})$ is a chronic-degenerative disease. The knee is the most commonly affected joint and the symptoms are generally attributed to quadriceps muscle weakness. However, few studies have evaluated this relationship in a population with early stages of knee OA. Objective: To investigate whether a correlation among the knee extensor torque and the three subscales of the WOMAC questionnaire in men with early stages of knee OA exists. Method: Twenty-one men with knee OA grades I or II (according to Kellgren and Lawrence* criteria) participated in this study. The concentric and eccentric knee extensor torque were assessed using a Biodex System 3 Pro ${ }^{\circledR}$ isokinetic dynamometer, at a speed of $90 \%$ s. Self-reported symptoms and disability were assessed using the WOMAC questionnaire. Spearman's correlation coefficient was used to test the relationship between the dependent variables (three subscales of WOMAC questionnaire) and the independent variables (average knee extensor peak torque). Results: We found a strong negative correlation between the concentric extensor torque and pain $(r=-0.7, p<0.001)$ and a moderate and negative correlation among the concentric extensor torque and stiffness $(r=-0.62, p=0.002)$ and physical function $(r=-0.54, p=0.011)$. Eccentric extensor torque presented a moderate and negative correlation with the three subscales of the WOMAC ( $r=-0.40$ to $0.69, p<0.05$ ). Conclusions: The concentric and eccentric knee extensor torque is significantly correlated with self-report symptoms of patients in initial stages of knee OA. Therefore, the strengthening of the quadriceps muscles, through concentric and eccentric exercise is indicated for these patients in order to minimize these symptoms.

Trial registration: number RBR-8q4zfh
\end{abstract}

Keywords: physical therapy; knee osteoarthritis; WOMAC; muscle strength.

\section{Resumo}

Contextualização: A osteoartrite (OA) é uma doença crônico-degenerativa. O joelho é a articulação mais afetada, e os sintomas geralmente são atribuídos à fraqueza do músculo quadríceps. Entretanto, poucos estudos têm avaliado essa relação em indivíduos com graus iniciais de OA. Objetivo: Verificar se existe correlação entre o torque extensor do joelho e as seções dor, rigidez e função física do questionário WOMAC de homens com OA de joelho nos graus iniciais. Método: Participaram deste estudo 21 homens com OA de joelho graus I ou II (segundo critérios de Kelgren e Lawrence*). Foi avaliado o torque extensor concêntrico e o excêntrico do joelho por meio do dinamômetro isocinético (Biodex System 3 Pro ${ }^{\circledast}$ ), na velocidade de $90 \%$ s. O autorrelato de sintomas e incapacidades foi avaliado por meio do questionário WOMAC. O Coeficiente de Correlação de Spearman foi utilizado para detectar a relação entre as variáveis dependentes (três seções do questionário WOMAC) e as variáveis independentes (média dos picos de torque). Resultados: Encontrou-se correlação forte e negativa do torque extensor concêntrico com a seção dor $(r=-0,7, p<0,001)$ e moderada e negativa com as seções rigidez $(r=-0,62, p=0,002)$ e função física $(r=-0,54, p=0,011)$. O torque extensor excêntrico correlacionou-se moderada e negativamente com as três seções do questionário $(r=-0,40$ a -0,69, $p<0,05)$. Conclusões: Os torques extensores concêntrico e excêntrico correlacionaram-se com os sintomas autorrelatados pelos indivíduos com graus iniciais de OA de joelho. Assim, o fortalecimento do músculo quadríceps, por meio de exercícios concêntricos e excêntricos, é indicado para esses pacientes para minimizar tais sintomas.

Registro Ensaios Clínicos sob o número RBR-8q4zfh.

Palavras-chave: fisioterapia; osteoartrite de joelho; WOMAC; força muscular.

*Kellgren JH, Lawrence JS. Radiological assessment of osteo-arthrosis. Ann Rheum Dis. 1957;16(4):494-502.

Received: 10/04/2011 - Revised: 02/23/2012 - Accepted: 03/20/2012

Physical Therapy Department, Universidade Federal de São Carlos (UFSCar), São Carlos, SP, Brazil

Correspondence to: Stela Márcia Mattiello, Physical Therapy Department, Universidade Federal de São Carlos, Rodovia Washington Luiz, Km 235, Caixa Postal 676, CEP 13565-905, São Carlos, SP, Brasil, e-mail: stela@ufscar.br 


\section{Introduction $: \because$.}

Osteoarthritis (OA) is the most common musculoskeletal disease worldwide and is associated with significant societal and health $\operatorname{costs}^{1,2}$ with considerable impact on quality of life ${ }^{3,4}$. Individuals with knee OA experience joint stiffness, pain and physical dysfunction ${ }^{5-7}$.

Although the symptoms of knee OA are attributed to muscle weakness ${ }^{8}$, especially of the quadriceps muscle, there is no consensus in the literature regarding the relationship between the strength of this muscle and the symptoms experienced by individuals with knee $\mathrm{OA}^{9}$. While Slemenda et al. ${ }^{10}$ found that quadriceps muscle weakness was a strong predictor of knee pain and physical dysfunction, Steultjens et al. ${ }^{11}$ found that reduced muscle strength was associated with increased disability, but no relationship could be established between muscle weakness and pain. Controversy found between these studies may be due to the differences regarding muscle contraction type used for the quadriceps muscle strength assessment (concentric in the study by Slemenda et al. ${ }^{10}$ and isometric in the study by Steultjens et al. ${ }^{11}$ ), the way pain was evaluated (by the WOMAC in the study by Slemenda et $a .^{10}$ and by the visual analogue scale - VAS - in the study by Steultjens et al. ${ }^{11}$ ), as well as due to the different OA degrees the evaluated subjects presented (OA degree equal 2 or higher in the study by Slemenda et al. ${ }^{10}$ and all OA degrees in the study by Steultjens et al..$^{11}$ ).

Few studies have evaluated this relationship in a population with early stages of knee $\mathrm{OA}^{11}$. Generally, studies have evaluated patients with advanced $\mathrm{OA}^{12,13}$ or have included patients with mild, moderate and severe OA in the same study group ${ }^{14,15}$, making it impossible to extrapolate the results to populations in the early stages of OA. Thus, a study evaluating the relationship between the strength of the quadriceps muscle and the symptoms experienced by individuals with early stages of knee $\mathrm{OA}$ is relevant, especially with regards to the design of rehabilitation programs. If correlations between the quadriceps muscle strength and symptoms were detected, it is expected that a muscle-strengthening protocol would be able to reduce the symptoms of patients with early stages of knee OA.

The strength of the quadriceps muscle in patients with knee OA has been measured isometrically in most studies ${ }^{8,16-18}$. However, it is possible that changes in the ability to generate force at entire range of motion are not detected in isometric assessments. Thus, because the evaluation of concentric and eccentric contractions allows quantification of the capacity to generate torque for the entire range of motion, it is possible that this assessment technique is more sensitive and thus better able to detect decreases in muscle strength in individuals with knee OA. It is worth noting that precise coordination of quadriceps muscle activity and knee joint movement is essential to mitigate force and control joint load during locomotion. This coordination is required because knee movement control occurs when weight is transferred to the support limb, a process that acts to dissipate the load. This process requires eccentric action of the quadriceps muscle ${ }^{1}$. The decrease in eccentric strength of the quadriceps muscle is particularly important in the pathogenesis and progression of knee OA, which makes the study of eccentric strength even more relevant in the population with early stages of this disease.

For a clinical profile, the Western Ontario McMaster Universities Osteoarthritis Index (WOMAC questionnaire) is one the most widely used self-report outcome measure of lower-extremity symptoms and function ${ }^{2}$. There are no studies in the reviewed literature that have correlated the concentric and eccentric strengths of the quadriceps muscle with the three WOMAC questionnaire subscales. The studies that have evaluated these muscle actions correlated the concentric and/or eccentric strengths with the time needed to perform some functional tasks ${ }^{19,20}$. However, these functional tests may not be directly related to the performance of individuals in their habitual activities. Thus, the individuals perceptions of their physical function, such as that evaluated by the WOMAC questionnaire, may be relevant.

Therefore the objectives of this study were to determine whether correlations among concentric and eccentric knee extensor torque and the pain, stiffness and physical function subscales of the WOMAC questionnaire in men with Grade I or II knee OA exist. Although the volunteers were in the initial stages of OA, we hypothesized that the lower knee extensor torque in these individuals would already be associated with greater pain, stiffness and functional disability.

\section{Method $: \because$.}

\section{Participants}

Twenty-seven subjects with knee OA were evaluated. The subjects were recruited from the physical therapy clinic at the Universidade Federal de São Carlos (UFSCar), São Carlos, SP, Brazil and from the community. The following inclusion criteria were used: male, sedentary, aged between 40 and 65 years, unilateral or bilateral knee OA diagnosed according to the clinical criteria of the American College of Rheumatology ${ }^{21}$ and grade I or II of knee OA according the Kellgren and Lawrence ${ }^{22}$ criteria. Six subjects did not meet the inclusion criteria (presented grade III of knee OA). Thus, a total of twenty-one subjects were included in this study. 
Standing axial, antero-posterior and lateral radiographs of both knees from each of the subjects were obtained to confirm that the subjects presented signs of $\mathrm{OA}$, such as the presence of minimal osteophytes (grade I) or small but definite osteophytes (grade II) in at least one of the compartments of the knee joint (tibiofemoral or patellofemoral) ${ }^{23}$. Severity of OA was graded by a radiologist according the Kellgren and Lawrence ${ }^{22}$ criteria.

The exclusion criteria were: physical therapy treatment over the last 12 months; knee or hip surgery; history of lower limb trauma; corticosteroid infiltration of the knee (previous 6 months) ${ }^{1}$; medical conditions affecting the cardiovascular, respiratory, neurological and/or musculoskeletal systems ${ }^{15}$. The study was approved by the Ethics Committee on Human Research at the UFSCar ( ${ }^{\circ}$. 143/2007), and all participants provided written informed consent.

\section{Instruments and procedures}

The affected or more severe limb (in cases of bilateral OA) was assessed ${ }^{1}$. Weight and height were obtained from the participants and the body mass index was calculated.

\section{Isokinetic evaluation}

The muscle strength was assessed using an isokinetic dynamometer (Biodex Multi-Joint System 3, Biodex Medical Inc., NY, USA). The order of testing was randomly determined, through a drawing. Prior to the evaluation, the isokinetic dynamometer was calibrated according to the manual provided by the equipment manufacturer.

Before the evaluation, the subject performed a warm up on a stationary bike for five minutes at a workload of $75 \mathrm{~W}$ and a speed of $20 \mathrm{~km} / \mathrm{h}$, and performed self-stretching exercises for the lower limb muscles.

We evaluated the concentric and eccentric extensor torques of the knee at a speed of $90^{\circ} / \mathrm{s}$. The evaluations were conducted with the volunteer seated on the device chair, stabilized by a belt that ran across the trunk and the pelvic girdle and with the knee flexed at 90 degrees. The rotational axis of the dynamometer was aligned with the lateral epicondyle of the femur; the resistance was applied at $5 \mathrm{~cm}$ above the medial malleolus.

The subjects were instructed to keep their arms crossed in front of their trunk during the test to avoid compensation. After receiving the test instructions, the subjects performed five maximal concentric and eccentric isokinetic contractions with a range of motion from $20^{\circ}$ to $90^{\circ}$ (being 0 degrees meaning full knee extension). The rest between each type of contraction was of 5 minutes duration ${ }^{12}$. Prior to each assessment, the subjects
Table 1. Characteristics of patients with knee OA.

\begin{tabular}{lc}
\hline Characteristics & Subjects $(\mathrm{n}=21)$ \\
\hline Age $(\mathrm{y})$ & $51.80 \pm 6.23$ \\
\hline Height $(\mathrm{m})$ & $1.71 \pm 0.06$ \\
\hline Weight $(\mathrm{kg})$ & $86.66 \pm 10.82$ \\
\hline BMI $(\mathrm{kg} / \mathrm{m} 2)$ & $29.62 \pm 4.22$ \\
\hline Radiologic evidence of OA (\%) & \\
\hline \multicolumn{1}{c}{$\mathrm{K} / \mathrm{L}$ degree I } & 45.5 \\
\hline K/L degree II * & 54.5 \\
\hline
\end{tabular}

Values are mean $\pm S D$; *values are the number of participants (percentage). BMI=Body mass index; $\mathrm{K}$ / L=Kellgren and Lawrence score.

Table 2. Descriptive data of knee extensor torque (BW) of OA participants.

\begin{tabular}{lc}
\hline $\begin{array}{l}\text { Knee extensor torque } \\
(\mathrm{Nm} / \mathrm{kg} \times 100)\end{array}$ & Median (max-min) $(\%)$ \\
\hline Concentric & $141.34(198.80-54.14)$ \\
\hline Eccentric & $179.04(272.20-92.88)$ \\
\hline
\end{tabular}

Table 3. WOMAC pain, stiffness and physical function scores of OA subjects.

\begin{tabular}{lc}
\hline WOMAC & Median $(\max -\min )(\%)$ \\
\hline Pain & $15(70-0)$ \\
\hline Stifness & $0(62.5-0)$ \\
\hline Physical function & $11.76(54.41-0)$ \\
\hline
\end{tabular}

Table 4. Spearman product-moment correlation coefficients between concentric and eccentric knee extensor torque and the WOMAC's sections in men with $\mathrm{OA}$ degrees I or II.

\begin{tabular}{lcccc}
\hline \multirow{2}{*}{ WOMAC score } & \multicolumn{2}{c}{ Concentric } & \multicolumn{2}{c}{ Eccentric } \\
\cline { 2 - 5 } & $r$ & $p$ value & $r$ & $p$ value \\
\hline Pain & -0.70 & $<0.001^{*}$ & -0.56 & $0.008^{*}$ \\
\hline Stifness & -0.62 & $0.002^{*}$ & -0.44 & $0.046^{\star}$ \\
\hline Physical function & -0.54 & $0.011^{*}$ & -0.52 & $0.015^{\star}$ \\
\hline
\end{tabular}

${ }^{*} \mathrm{P}<0.05=$ significant relationship .

performed three submaximal contractions to familiarize themselves with the procedure. We used verbal commands to encourage the patients to produce maximum torque during the contractions ${ }^{15}$.

During the strength assessment, volunteers should not present pain. However, two of them reported pain on the test day; thus, the test was cancelled and rescheduled. Therefore, no volunteer presented pain during the tests.

The torque data, measured in Nm, were normalized by body weight (in $\mathrm{kg}$ ) using the following formula: (Nm torque $/ \mathrm{kg}$ body weight) $\mathrm{X} 100^{24}$. For statistical analysis we used the mean of peak torque of five maximal contractions.

\section{WOMAC questionnaire}

The Western Ontario McMaster Universities Osteoarthritis Index (WOMAC) is a self-report questionnaire, designed to assess the problems experienced by individuals with lower limb OA. This questionnaire was translated and validated for 
Brazilian-Portuguese language ${ }^{3}$. Each item corresponds to a particular dimension (pain, stiffness and physical function). The scores for the items are expressed using a Likert scale where none $=0$, low $=25$, moderate $=50$, severe $=75$ and very severe $=100^{25}$. The maximum score in each section is expressed as a percentage, with higher scores indicating greater pain, stiffness and physical dysfunction.

\section{Statistical analysis}

Data were analyzed using the Statistica ${ }^{\circledR}$ software (version 7, StatSoft, Inc., Tulsa, USA). Initially, descriptive values (mean, standard deviation, median, maximum and minimum) were obtained for all data. Then, the normality of data was checked using the Shapiro-Wilk test. None of the study variables were normally distributed. We used the Spearman's $r$ correlation coefficients to analyze the relationship between the dependent variables (WOMAC subscales for pain, stiffness and physical function) and the independent variables (the normalized mean peak knee concentric and eccentric extensor torques). The $r$ values were interpreted using the following categories: 0.00 to $0.19=$ none $/$ mild; 0.20 to $0.39=$ low; 0.40 to $0.69=$ moderate; 0.70 to $0.89=$ strong; and 0.9 to $1.00=$ very strong ${ }^{26}$. For all the statistical tests, the significance level was set at $\mathrm{p}<0.05$. Power analysis was performed using SigmaPlot (11.0, Systat Software, Inc), considering the correlation between concentric extensor torque and pain and the correlation between eccentric extensor torque and pain. According to our data (correlation coefficients $=0.7$ and 0.56 for two correlations, respectively; $\mathrm{n}=21$ subjects, and an alpha level set at 0.05 ), the statistical power were 0.95 or $95 \%$.

\section{Results $: \because$.}

The demographic characteristics of the study participants are described in Table 1. Grade I OA was found in $45.5 \%$ of the subjects and Grade II in 54.5\%.

The knee compartment affected by OA was identified through radiological examination. One subject presented OA only in the patellofemoral $(\mathrm{PF})$ compartment, three in the medial tibiofemoral (MTF) compartment, and one in the lateral tibiofemoral (LTF) compartment. Combined affected compartments were found in sixteen subjects: PF plus MTF was found in 5 subjects, PF plus LTF in three subject, and PF plus MTF and LTF in 8 subjects.

Tables 2 and 3, respectively, present the descriptive values for knee extensor torque and the three subscales of the WOMAC questionnaire (pain, stiffness and physical function).
Significant correlations were found between knee extensor torque and the three WOMAC questionnaire subscales. The concentric extensor torque presented a strong and negative correlation with the pain subscale $(r=-0.7, \mathrm{p}<0.001)$ and a moderate and negative correlation with the stiffness $(r=-0.62$, $\mathrm{p}=0.002)$ and physical function subscales $(r=-0.54, \mathrm{p}=0.011)$. Eccentric extensor torque presented a moderate and negative correlation with the three questionnaire subscales (Table 4). These negative correlations indicate that the higher the knee extensor torque (both concentric and eccentric), the less pain and stiffness and the lower the level of physical dysfunction.

\section{Discussion $: \because$.}

It is well documented in the literature that individuals with knee OA present a deficit in quadriceps muscle strength compared to healthy individuals of similar ages ${ }^{16,27,28}$. However, we found no studies in the reviewed literature that assessed the relationships among concentric and eccentric quadriceps muscle strength and the self-reported symptoms of patients with early stages of knee OA. Given that WOMAC is an outcome measure with three established subscales, all analysis were performed for each subscale 2 . Thus, this study aimed to evaluate the correlations among the knee extensor torque and pain, stiffness and functional impairment in men with Grades I and II of knee OA.

In accordance with our hypothesis, the data analysis revealed a strong negative correlation between the concentric knee extensor torque and the responses to the pain section of the WOMAC questionnaire and a moderate negative correlation between the extensor eccentric torque and these same responses for men with early stages of knee OA. These results indicate that the greater knee extensor torque is, the lower the level of pain that is self-reported by these individuals.

It is reported in the literature that the quadriceps muscle is an important structure in the absorption of impacts experienced by the knee joint, especially through the eccentric action of this mus$\operatorname{cle}^{29}$. Therefore, the strength deficits in this muscle can compromise its role in absorbing loads ${ }^{1,12}$. Considering that individuals with knee OA usually present weakness of the quadriceps muscle, we suggest that these patients experience increased joint loading, which could contribute to increased pain. This partially explains the relationship between knee extensor torque and pain found in this study.

These findings are not in agreement with those of the studies of Steultjens et al. ${ }^{11}$, who found no correlation between quadriceps muscle weakness and pain in individuals with knee OA. These authors evaluated the isometric strength of the quadriceps muscles in patients with knee OA using a hand-held dynamometer. Isometric testing evaluates the joint torque only in the knee angle pre-determined 
by the evaluator. Thus, our evaluation may have been more sensitive because the knee extensor torque was evaluated over a greater range of motion, from $90^{\circ}$ to $20^{\circ}$ of knee flexion $\left(0^{\circ}\right.$ corresponds to full knee extension). It should be emphasized that peak torque represents the maximal torque achieved at a single angle in the range of motion evaluated. Nonetheless, that differs from evaluating the isometric strength at a single angle. First, when the isometric strength is evaluated, angles used might not correspond to the ones in which the maximal torque is produced. Second, for one angle, it is possible that the torque produced during a dynamic action be different from the torque produced during a static action (isometric action), due to the strength-velocity relationship ${ }^{30}$. This may explain the fact that our study showed correlations between symptoms and knee extensor torque, and the study by Steultjens et al. ${ }^{11}$ did not.

Zacaron et al. ${ }^{7}$ found no correlation between the total work of the quadriceps muscle, during concentric contraction, and pain in individuals with knee OA. It should be noted, however, that these authors assessed pain using a visual analogical scale, which also may not represent the perception of pain of these individuals in their usual activities. Moreover, Vasconcelos, Dias and Dias ${ }^{31}$ found correlation between the pain section of the WOMAC questionnaire and functional capacity. These findings emphasize the importance of pain assessment using this questionnaire.

Although the volunteers who participated in this study had degreeI or II knee OA, our results indicate that correlations between the concentric and eccentric knee extensor torque and physical function are already present. These results also indicate that the lower the muscle strength, the greater the functional deficit. Although they evaluated subjects with various stages of knee OA, some studies also found a correlation between quadriceps muscle weakness and functional disability ${ }^{19,32,33}$, in agreement with our results.

Gür et al. ${ }^{19}$ found weak to moderate correlations between knee flexor and extensor torque and the time to perform some tasks (walking and ascending and descending stairs) and between these torques and pain in patients with OA grade II or III. Hortobágyi et al. ${ }^{12}$ found a moderate negative correlation between quadriceps muscle strength (expressed as the sum of the maximum isometric, concentric and eccentric forces) and the time spent by patients with knee OA, grade II or greater, to perform functional tasks. It should be emphasized that the physical function section of the WOMAC questionnaire covers several functional activities that require concentric and eccentric contractions of the quadriceps muscle. This could be a possible explanation for the negative correlation between the concentric and eccentric knee extensor torques and the responses for this section of the WOMAC questionnaire that was found in the present study.

Joint stiffness is a clinical symptom extensively studied in reference to knee OA. In this study, the stiffness subscale was also negatively correlated with the quadriceps muscle strength, indicating that the lower the strength of the muscle is, the greater the stiffness reported by the patients. An epidemiologic study ${ }^{10}$ of joint damage in an osteoarthritis community population concluded that quadriceps weakness might precede radiologic joint damage, and Sanghi et al. ${ }^{2}$ found that in linear regression models the articular incongruences as a significant predictor of stiffness. Because the degree of congruity between the loading surfaces of the condyle varies depending on condylar position, if there is no lateral subluxation or tilt the knee joint is congruent. In knee OA, differential degeneration of cartilage creates incongruities between loadings due to the shift in the mechanical axis of weight bearing. Such a change in joint kinematics persisting over time may cause abnormal stresses that result in gradual cartilage fatigue, which can progress to changes leading to stiffness in $\mathrm{OA}^{2}$. This can explain the correlation between quadriceps weakness and stiffness in these patients. However, no studies have been found that have examined this correlation in early stages of knee OA, and for this reason a comparison with other studies was not possible.

It is important to highlight that our study sample was carefully selected; we assessed only males, of whom $45.5 \%$ had Grade I knee OA and 54.5\% had Grade II OA. Only men were included to avoid the confounding hormonal effects of estrogen levels in women. Because estrogen is chondroprotective and because its level declines after menopause, the incidence of OA in women in this age group (40-65 years) may vary according to the levels of hormones present ${ }^{34}$. Moreover, because the present study assessed only men, and given that there may be differences between genders, the exclusion of women can be considered a limitation of this study. Thus, future studies on the relationship of self-reported symptoms and muscle weakness should be performed in women with early stages of knee OA.

Another limitation to this study must be considered. The fact that this study used a transversal design does not allow causal inferences to be made regarding the relationships among the variables studied.

To conclude, in the early stages of knee OA, concentric and eccentric knee extensor torque are already negatively correlated with patient self-reports of pain, stiffness and physical dysfunction. Thus, rehabilitation programs that include strengthening of the quadriceps muscle, through concentric and eccentric exercise, is indicated for these patients, in order to improve muscle strength and to reduce pain and improve to function.

\section{Acknowledgments : :}

The Fundação de Amparo a Pesquisa do Estado de São Paulo (FAPESP), São Paulo, Brazil for financial support (\#2007/07200-4; \#2011/06619-7). 


\section{References: : :}

1. Hinman RS, Bennell KL, Metcalf BR, Crossley KM. Delayed onset of quadriceps activity and altered knee joint kinematics during stair stepping in individuals with knee osteoarthritis. Arch Phys Med Rehabil. 2002;83(8):1080-6.

2. Sanghi D, Avasthi S, Mishra A, Singh A, Agarwal S, Srivastava RN. Is radiology a determinant of pain, stiffness an functional disability in knee osteoarthritis? A cross-sectional study. J Orthop Sci. 2011;16(6):719-25.

3. Santos ML, Gomes WF, Pereira DS, Oliveira DMG, Dias JMD, Ferrioli E, et al. Muscle strength, muscle balance, physical function and plasma interleukin-6 (IL-6) levels in elderly women with knee osteoarthritis (OA). Arch Gerontol Geriatr. 2011;52(3):322-6.

4. Muraki S, Akune T, Oka H, En-yo Y, Yoshida M, Saika A, et al. Association of radiographic and symptomatic knee osteoarthritis with health-related quality of life in a population-based cohort study in Japan: the ROAD study. Osteoarthritis Cartilage. 2010;18(9):1227-39.

5. Dieppe PA, Lohmander LS. Pathogenesis and management of pain in osteoarthritis. Lancet. 2005;365(9463):965-73

6. Zhang Y, Jordan JM. Epidemiology of osteoarthritis. Clin Geriatr Med. 2010;26(3):355-69.

7. Zacaron KAM, Dias JMD, Abreu NS, Dias RC. Nível de atividade física, dor e edema e suas relações com a disfunção muscular do joelho de idosos com osteoartrite. Rev Bras Fisioter. 2006;10(3):279-84

8. Palmieri-Smith RM, Thomas AC, Karvonen-Gutierrez C, Sowers MF. Isometric quadriceps strength in women with mild, moderate, and severe knee osteoarthritis. Am J Phys Med Rehabil. 2010;89(7):541-8

9. Bennell KL, Hunt MA, Wrigley TV, Lim BW, Hinman RS. Role of muscle in the genesis and management of knee osteoarthritis. Rheum Dis Clin North Am. 2008;34(3):731-54.

10. Slemenda C, Brandt KD, Heilman DK, Mazzuca S, Braunstein EM, Katz BP, et al. Quadriceps weakness and osteoarthritis of the knee. Ann Intern Med. 1997;127(2):97-104.

11. Steultjens MPM, Dekker J, van Baar ME, Oostendorp RAB, Bijlsma JWJ. Muscle strength, pain and disability in patients with osteoarthritis. Clin Rehabil. 2001;15(3):331-41.

12. Hortobágyi T, Garry J, Holbert D, Devita P. Aberrations in the control of quadriceps muscle force in patients with knee osteoarthritis. Arthritis Rheum. 2004;51(4):562-9

13. Røgind $H$, Bibow-Nielsen B, Jensen B, Møller HC, Frimodt-Møller $H$, Bliddal $H$. The effects of a physical training program on patients with osteoarthritis of the knees. Arch Phys Med Rehabil. 1998;79(11):1421-7

14. Bennell KL, Hinman RS, Metcalf BR, Crossley KM, Buchbinder R, Smith M, et al Relationship of knee joint proprioception to pain and disability in individuals with knee osteoarthritis. J Orth Research. 2003;21(5):792-7.

15. Hassan BS, Mockett S, Doherty M. Static postural sway, proprioception, and maximal voluntary quadriceps contraction in patients with knee osteoarthritis and normal control subjects. Ann Rheum Dis. 2001;60(6):612-8.

16. O'Reilly SC, Jones A, Muir KR, Doherty M. Quadriceps weakness in knee osteoarthritis: the effect on pain and disability. Ann Rheum Dis. 1998;57(10):588-94

17. van der Esch M, Steultjens M, Harlaar J, Knol D, Lems W, Dekker J. Joint proprioception, muscle strength, and functional ability in patients with osteoarthritis of the knee. Arthritis Rheum. 2007;57(5):787-93
18. Hurley MV, Scott DL, Rees J, Newham DJ. Sensorimotor changes and functional performance in patients with knee osteoarthritis. Ann Rheum Dis. 1997;56(11):641-8.

19. Gür H, Cakin N, Akova B, Okay E, Küçükoglu S. Concentric versus combined concentric-eccentric isokinetic training: effects on functional capacity and symptoms in patients with osteoarthrosis of the knee. Arch Phys Med Rehabil. 2003;83:308-16.

20. Bennell KL, Hinman RS, Metcalf BR. Association of sensorimotor function with knee joint kinematics during locomotion in knee osteoarthritis. Am J Phys Med Rehabil. 2004;83(6):455-63.

21. Recommendations for the medical management of osteoarthritis of the hip and knee: 2000 update. American College of Rheumatology Subcommittee on Osteoarthritis Guidelines. Arthritis Rheum. 2000;43(9):1905-15

22. Kellgren JH, Lawrence JS. Radiological assessment of osteo-arthrosis. Ann Rheum Dis 1957;16(4):494-502

23. Lessi GC, Serrão PRMS, Gimenez ACF, Gramani-Say K, Oliveira AB, Mattiello SM. Male subjects with early-stage knee osteoarthritis do not present biomechanical alterations in the sagital plane during stair descent. Knee. 2011;doi:10.106/j.knee.2011.07.001.

24. Robinson RL, Nee RJ. Analysis of hip strength in females seeking physical therapy treatment for unilateral patellofemoral pain syndrome. J Orthop Sports Phys Ther. 2007;37(5):232-8.

25. Kirkwood RN, Resende RA, Magalhães CMB, Gomes HA, Mingoti SA, Sampaio RF. Application o principal component analysis on gait kinematics in elderly women with knee osteoarthritis. Rev Bras Fisioter. 2011;15(1):52-8.

26. Weber JC, Lamb DR. Statistics and Research in Physical Education. Saint Luis: C.V: Mosby Company; 1970

27. Stevens JE, Mizner RL, Snyder-Mackler L. Quadriceps strength and volitional activation before and after total knee arthroplasty for osteoarthritis. J Orthop Res. 2003;21(5):775-9.

28. Thomas MJ, Wood L, Selfe J, Peat G. Anterior knee pain in younger adults as a precursor to subsequent patellofemoral osteoarthritis: a systematic review. BMC Musculoskelet Disord. 2010;11:201.

29. LaStayo PC, Woolf JM, Lewek MD, Snyder-Mackler L, Reich T, Lindstedt SL. Eccentric muscle contractions: their contribution to injury, prevention, rehabilitation, and sport. J Orthop Sports Phys Ther. 2003;33(10):557-71.

30. Westing SH, Seger JY, Thorstensson A. Effects of electrical stimulation on eccentric and concentric torque-velocity relationships during knee extension in man. Acta Physiol Scand. 1990;140(1):17-22

31. Vasconcelos KSS, Dias JMD, Dias RC. Relação entre intensidade de dor e capacidade funciona em indivíduos obesos com osteoartrite de joelho. Rev Bras Fisioter. 2006;10(2):213-8.

32. Slemenda C, Heilman DK, Brandt KD, Katz BP, Mazzuca SA, Braunstein EM, et al. Reduced quadriceps strength relative to body weight: a risk factor for knee osteoarthritis in women? Arthritis Rheum. 1998;41(11):1951-9.

33. Hurley MV, Newham DJ. The influence of arthrogenous muscle inhibition on quadriceps rehabilitation of patients with early, unilateral osteoarthritic knees. $\mathrm{Br} J$ Rheumatol. 1993;32(2):127-31

34. Sowers MR, McConnell D, Jannausch M, Buyuktur AG, Hochberg M, Jamadar DA. Estradiol and its metabolites and their association with knee osteoarthritis. Arthritis Rheum. 2006;54(8):2481-7. 